\title{
Knowledge and attitudes of Latin American gynecologists regarding unplanned pregnancy and use of combined oral contraceptives
}

This article was published in the following Dove Press journal:

International Journal of Women's Health

4 May 2015

Number of times this article has been viewed

\author{
Luis Bahamondes' \\ Josefina Lira-Plascencia ${ }^{2}$ \\ Ricardo Martin ${ }^{3}$ \\ Victor Marin ${ }^{4}$ \\ Maria Y Makuch' \\ 'Department of Obstetrics and \\ Gynecology, School of Medical \\ Sciences, University of Campinas \\ (UNICAMP), Campinas, Brazil; \\ ${ }^{2}$ Instituto Nacional de Perinatología, \\ México, DF, México; ${ }^{3}$ Hospital \\ Universitario, Fundación Santa Fe de \\ Bogotá, Bogotá, Colombia; ${ }^{4}$ Hospital \\ Central, Petróleos Mexicanos, México, \\ DF, México
}

Background: Unintended pregnancy is a public health problem and unmet medical need worldwide. It is estimated that in the year 2012, almost 213 million pregnancies occurred, and the global pregnancy rate decreased only slightly from 2008 to 2012. It was also estimated that 85 million pregnancies ( $40 \%$ of all pregnancies) were unintended and that $38 \%$ ended in an unintended birth.

Objectives: To assess knowledge and attitudes of Latin American (LA) obstetricians and gynecologists (OBGYNs) regarding unintended pregnancies and aspects of combined oral contraceptive (COC) use.

Methods: A survey was conducted during a scientific meeting about contraception in 2014, in which OBGYNs from 12 LA countries who provide attention in contraception were invited to respond to a multiple-choice questionnaire to assess their knowledge and attitudes regarding unplanned pregnancy and some aspects regarding COC use.

Results: A total of 210 OBGYNs participated in the study. Their knowledge regarding COC failure was low. The participants reported they believed that their patients habitually forgot to take a pill and that their patients did not know what to do in these situations. They were aware of the benefits of COC use; however, they were less prone to prescribe COCs for the purpose of protecting against ovarian and endometrial cancer, and one-quarter of them had doubts about the association between $\mathrm{COC}$ use and cancer risk.

Conclusion: The interviewed LA OBGYNs showed some flaws in terms of knowledge of COC failure rates and the non-contraceptive benefits and risks of COCs. To adequately counsel their patients regarding COC intake, OBGYNs must be updated regarding all aspects of COC use.

Keywords: contraception, unintended pregnancy, benefits of oral contraceptives

\section{Introduction}

Unintended pregnancy is a public health problem worldwide, both in developing and developed countries, that may pose burdens on children, women, men, and families, and contribute to maternal, infant, and child mortality. Also, it is responsible for a percentage of unsafe abortion in countries in which abortion is not legal as in most Latin American (LA) countries. ${ }^{1}$ It is estimated that in the year 2012, almost 213 million pregnancies occurred, and the global pregnancy rate decreased only slightly from 2008 to $2012 .{ }^{2}$ It was also estimated that 85 million pregnancies (40\% of all pregnancies) were unintended and that $38 \%$ ended in an unintended birth. ${ }^{2,3}$

A study that evaluated pregnancy rates by intention and outcome showed a worldwide decline of $17 \%$ of unintended pregnancy in both developed and developing countries from 1995 to 2008. Also, in 2008, a worldwide estimate showed that four out of ten pregnancies were unintended, with a higher proportion in South American 
countries and south Saharan Africa, where six in ten pregnancies were unintended. . $^{2,3}$

Family planning programs have an important role in the reduction of unintended pregnancies. The prevention of unintended pregnancies is a cost-effective strategy for health services, ${ }^{4}$ and it depends on coordinated actions on various fronts. It is desirable that governments take action to improve reproductive health services, including efficient family planning programs that offer contraceptive methods at an affordable cost, having adequate facilities, and training health care professionals (HCPs) in family planning, among other initiatives. HCPs play an important role in the reduction of the rate of unintended pregnancies, and this role is influenced by the knowledge, attitudes, and myths of these professionals regarding contraceptive methods.

Presently, there is no doubt that long-acting reversible contraceptives (intrauterine contraceptives and implants) have a higher contraceptive efficacy than combined oral contraceptives (COCs), vaginal rings, or patches ${ }^{5,6}$ because shorter-acting methods are user-dependent. The contraceptive efficacy for typical use is higher than for perfect use because daily or periodic attention of the user is required. ${ }^{5}$ Nevertheless, COCs are the first contraceptive that many women use after sexual debut and the main contraceptive option in many settings, with a prevalence of almost $25 \%$ in several LA countries. ${ }^{7}$ The use of any contraceptive method is influenced by both patients' and doctors' fears, myths, and misperceptions. Furthermore, knowledge regarding the risks is frequently higher than knowledge regarding the benefits among HCPs and women. ${ }^{8}$ In a Brazilian study, obstetricians and gynecologists (OBGYNs) reported that women frequently were afraid that hormone intake could affect their body, provoke infertility, increase weight, and in general were worried that hormones could affect their health. ${ }^{9}$ Furthermore, in a Canadian-based study, it was reported that $52 \%$ of the interviewed women indicated that they did not know what HCPs advised about the use of COC and the risk of uterine and ovarian cancer. ${ }^{10}$

It is important that OBGYNs and other HCPs are aware of the updated scientific information regarding contraceptive methods because better-informed HCPs are able to transmit correct information to users and potential users and, consequently, improve the quality of typical use. This study was conducted with the objective of assessing the knowledge and attitudes of a group of LA OBGYNs regarding unintended pregnancies and some aspects of the use and prescription of COCs.

\section{Material and methods Design}

The study was conducted in the second quarter of 2014, during a scientific meeting in Chile that was specifically designed to provide information about contraceptive methods. All the participants were OBGYNs from 12 LA countries (Argentina, Bolivia, Brazil, Chile, Colombia, Costa Rica, Ecuador, Guatemala, Mexico, Paraguay, Peru, and Venezuela) who provided regular consultation in contraception in their clinical practice. The study protocol received approval from the Ethical Committee of the University of Campinas, Brazil. The objectives of the study and the voluntary nature of participation were explained to all the participants in the meeting, making it clear that by answering the questions, the OBGYNs were consenting to participate in the study. This procedure for obtaining consent was approved by the Ethical Committee.

\section{Data collection}

All the participants in the meeting were invited to respond to a multiple-choice questionnaire through an electronic system during the meeting at the end of each lecture. The questionnaire was designed to provide demographic information regarding the nationality, age, sex, training, and clinical experience in family planning of the participants. After characterization data were collected, the participants provided feedback on the lectures that they attended during the meeting. For this manuscript, the questions selected were related to unintended pregnancy worldwide and knowledge about some aspects of COCs, such as COC use and the risk of venous thromboembolism (VTE) and the risk of several cancers.

The questions were developed specifically for this study by the researchers and reviewed by an expert group of LA OBGYNs who did not participate in the meeting. The participants who agreed to take part in the study were provided with electronic keypads to answer the multiple-choice questionnaire. There were five questions for each issue, and five answer options based on the contents of each lecture. The questions on each theme had to be completed in $\sim 3$ minutes because after that time period, the system automatically blocked the ability to answer. After that, the system provided the audience with the response percentage for each question. One of the authors coordinated the explanation of the survey, as well as the distribution and collection of the electronic keypads. To guarantee anonymity, the keypads were only identified with a number. 


\section{Data analysis}

Initially, a descriptive simple analysis was performed on the dependent variable to examine the knowledge, attitudes, and practices regarding unintended pregnancy and $\mathrm{COC}$ use. Then, dependent variables were evaluated, taking into account age ( $\leq 49$ years, $\geq 50$ years), sex (male/female), and the sector in which the OBGYN worked (exclusively public, both private and public). The statistical tests used, according to the data obtained, were the Pearson's $\chi^{2}$, Yates' $\chi^{2}$, and Fisher's exact tests. The software used was SPSS v20.0. The significance was established at $P<0.05$.

\section{Results}

The total number of the OBGYNs participating in the meeting was 210 , and the number of respondents to each question ranged from $153(72.8 \%)$ to 191 (90.9\%). The mean ( \pm standard deviation) age of the OBGYNs who participated in the survey was $48.7 \pm 10.6$ years (ranged from 30 to 72 years). Eighty-eight (41.9\%) were female, and 122 (58.1\%) were male. Practicing only in the public sector was reported by five (2.4\%), OBGYNs practicing only in the private sector was reported by 81 (38.6\%), and practicing in both the public and private sectors was reported by $112(55.3 \%)$.

\section{Awareness about unplanned pregnancies}

When the OBGYNs were asked about the prevalence of unintended pregnancies, most of them answered that African countries have the highest rate, followed by LA countries, with the exception of OBGYNs who worked in both the public and private sectors. The majority of these physicians responded that the rate in LA countries was similar to those in other developing countries. Furthermore, the majority of the OBGYNs, independent of age or sex, reported that the incidence of unintended pregnancy is higher among adolescents and that it has a social impact. Also, the OBGYNs were asked why women had elective abortions, and the majority answered that most of the women who had elective abortions did so because they did not use contraception or had used it incorrectly (Table 1). No significant differences were observed regarding age, sex, or the sector in which the OBGYN worked.

\section{Knowledge and attitudes about COCs}

The second group of questions related to knowledge about some aspects of COC use. Only $\sim 50 \%$ of the HCPs were aware of $\mathrm{COC}$ failure rates given typical use, and those who were younger, were female, and worked in the public sector were more accurate regarding this figure. According to $\sim 50 \%$ of the interviewed HCPs, $\sim 30 \%$ of COC users forget at least one pill, and $\sim 45 \%$ of the HCPs reported that women do not know what to do when they forget to take a pill (Table 2). Only the age variable of the OBGYN ( $\geq 50$ years old) significantly affected the answer regarding the proportion of women using COCs who forget to take them $(P<0.046)$.

Table I Questions and answers regarding unintended pregnancies

\begin{tabular}{|c|c|c|c|c|c|c|}
\hline & \multicolumn{2}{|l|}{ Age (\%) } & \multicolumn{2}{|l|}{ Sex (\%) } & \multicolumn{2}{|c|}{ Working in (\%) } \\
\hline & $\leq 49$ years & $\geq 50$ years & Female & Male & $\begin{array}{l}\text { Public } \\
\text { sector }\end{array}$ & $\begin{array}{l}\text { Private/public } \\
\text { sector }\end{array}$ \\
\hline \multicolumn{7}{|l|}{ Unintended pregnancy rates are $(n=|9|)$ : } \\
\hline Similar in LA to developed countries & 5.6 & 8.0 & 4.5 & 8.2 & 8.2 & 5.4 \\
\hline Similar in LA to developing countries & 31.5 & 26.0 & 31.8 & 27.9 & 24.5 & 33.9 \\
\hline The highest worldwide in LA & 25.9 & 24.0 & 29.5 & 21.3 & 20.4 & 28.6 \\
\hline The highest worldwide in Africa & 37.1 & 42.0 & 34.1 & 42.5 & 47.0 & 32.2 \\
\hline \multicolumn{7}{|c|}{ Unintended pregnancy is more common among $(n=190)$ : } \\
\hline Adolescents & 79.5 & 66.7 & 69.2 & 66.1 & 76.8 & 69.7 \\
\hline Young adults & 12.3 & 19.3 & 20.0 & 13.5 & 9.0 & 22.4 \\
\hline All women & 8.2 & 14.0 & 10.8 & 10.4 & 14.3 & 7.9 \\
\hline \multicolumn{7}{|c|}{ Unintended pregnancy has a social impact $(n=190)$ : } \\
\hline Yes & 97.2 & 98.4 & 100.0 & 96.1 & 100.0 & 96.2 \\
\hline No & 2.8 & 1.6 & 0.0 & 3.9 & 0.0 & 3.8 \\
\hline \multicolumn{7}{|c|}{ In your opinion, regarding the women who opt for an abortion $(n=|9|)$ : } \\
\hline Most do not use a contraceptive & 54.3 & 58.6 & 58.3 & 54.3 & 61.8 & 52.0 \\
\hline Most use a contraceptive incorrectly & 44.3 & 36.2 & 41.7 & 40.0 & 32.7 & 46.7 \\
\hline $\begin{array}{l}\text { Most use a fertility awareness method } \\
\text { or were victims of sexual abuse }\end{array}$ & 1.4 & 5.2 & 0.0 & 5.7 & 5.5 & 1.3 \\
\hline
\end{tabular}

Abbreviation: LA, Latin American. 
Table 2 Questions and answers regarding some aspects of use of COCs

\begin{tabular}{|c|c|c|c|c|c|c|c|}
\hline & \multicolumn{2}{|l|}{ Age (\%) } & \multicolumn{2}{|l|}{ Sex (\%) } & \multicolumn{2}{|c|}{ Working in (\%) } & \multirow[t]{2}{*}{$P$-value } \\
\hline & $\leq 49$ years & $\geq \mathbf{5 0}$ years & Female & Male & $\begin{array}{l}\text { Public } \\
\text { sector }\end{array}$ & $\begin{array}{l}\text { Private/public } \\
\text { sector }\end{array}$ & \\
\hline \multicolumn{8}{|c|}{ Failure rate of $C O C$ given typical use $(n=175)$ : } \\
\hline $1 \%-2 \%$ & 32.5 & 34.4 & 38.0 & 30.0 & 32.7 & 34.5 & \\
\hline $4 \%$ & 16.2 & 24.1 & II.I & 27.1 & 17.3 & 21.0 & \\
\hline $8 \%$ & 31.1 & 29.3 & 28.6 & 31.4 & 32.7 & 28.4 & \\
\hline $10 \%$ & 20.3 & 12.1 & 22.2 & 11.4 & 17.3 & 16.0 & \\
\hline \multicolumn{7}{|c|}{ According to the OBGYNs, the proportion of women using COCs who recognize forgetfulness $(n=153)$ : } & 0.046 \\
\hline $5 \%-10 \%$ & 9.8 & 27.0 & 23.4 & 12.5 & 16.0 & 18.7 & \\
\hline $30 \%$ & 49.3 & 42.9 & 42.2 & 51.4 & 46.0 & 47.7 & \\
\hline $50 \%$ & 23.9 & 20.6 & 20.3 & 23.6 & 26.0 & 19.8 & \\
\hline $70 \%$ & 16.9 & 9.5 & 14.1 & 12.5 & 12.0 & 14.0 & \\
\hline \multicolumn{8}{|c|}{ According to the OBGYNs the proportion of women who recognize they forget at least one COC pill per month ( $n=173)$ : } \\
\hline$<30 \%$ & 49.3 & 50.8 & 54.1 & 47.8 & 53.8 & 48.7 & \\
\hline $50 \%$ & 39.1 & 32.2 & 37.7 & 33.3 & 34.6 & 35.9 & \\
\hline $70 \%$ & 8.7 & 10.2 & 6.6 & 11.6 & 11.5 & 7.7 & \\
\hline$\geq 90 \%$ & 2.8 & 6.8 & 1.6 & 7.2 & 0.0 & 7.7 & \\
\hline \multicolumn{8}{|c|}{ According to OBGYNs, if women forget to take a pill $(n=175)$ : } \\
\hline $\begin{array}{l}\text { They know what to do } \\
\text { when they forget } 2-3 \text { pills }\end{array}$ & 29.7 & 15.8 & 22.0 & 23.8 & 17.7 & 26.0 & \\
\hline $\begin{array}{l}\text { They understand the } \\
\text { instructions }\end{array}$ & 14.0 & 19.3 & 17.0 & 15.9 & 13.3 & 18.2 & \\
\hline They follow the instructions & 17.2 & 14.0 & 20.3 & 11.1 & 20.0 & 13.0 & \\
\hline $\begin{array}{l}\text { They do not know what } \\
\text { to do }\end{array}$ & 39.1 & 50.9 & 40.7 & 49.2 & 48.9 & 42.9 & \\
\hline
\end{tabular}

Abbreviations: COC, combined oral contraceptive; OBGYNs, obstetricians and gynecologists.

Furthermore, the OBGYNs were asked if women were aware of the non-contraceptive benefits of COC use, and most of the respondents answered that less than $20 \%$ were aware of these benefits. They also reported that their patients are seeking dysmenorrhea and premenstrual syndrome (PMS) relief, the reduction of acne and hirsutism, no weight increase, and a reduction in both bleeding flow and number of menstrual cycles in equal numbers. Additionally, the HCPs reported that dysmenorrhea and the relief of PMS, as well as a reduction of acne and hirsutism, are the main benefits they considered when prescribing COCs (Table 3). Again, no significant differences were observed regarding age, sex, or the sector in which the OBGYN worked.

Regarding the block of questions about VTE and cancer risk related with $\mathrm{COC}$ use, it was observed that almost all of the HCPs were aware of the VTE risk associated with COCs. However, most of them were not aware of the relationship between the length of COC use and the risk of VTE, although most of the respondents were aware of the incidence of VTE among COC users. Finally, between $12 \%$ and $25 \%$ of the respondents had doubts about the relationship between COC use and cancer risk, with no significant differences regarding age, sex, or the sector in which the OBGYN worked (Table 4).

\section{Discussion}

It is estimated that in developed countries, unintended pregnancies accounted for more than $40 \%$ of pregnancies, ${ }^{11-13}$ and at least one-third of the $\sim 180$ million pregnancies that occur annually in developing countries are unintended. ${ }^{13}$ In many settings, unintended pregnancies are a consequence of the high cost of contraceptives, poor knowledge among women regarding contraception, inadequate distribution of contraceptives, myths (mainly associated to hormonal contraceptives and intrauterine contraceptives), a lack of HCPs available to provide this kind of service, or a lack of HCP training regarding the provision of contraceptives, mainly for those that require the active participation of a HCP, such as long-acting reversible contraceptive methods. ${ }^{6,14,15}$

Unintended pregnancies commonly end in elective abortion, and in most of the LA countries, abortion is not legal. Therefore, the procedure has frequent health consequences, and when it is available, it is only available in a restricted manner. ${ }^{13}$ The OBGYNs interviewed in this study stated that women who opt for abortion often either did not use or incorrectly used contraceptive methods.

Furthermore, many unintended pregnancies occur due to contraceptive failure. In the case of COC use, although the 
Table 3 Questions and answers about benefits of COCs

\begin{tabular}{|c|c|c|c|c|c|c|}
\hline & \multicolumn{2}{|l|}{ Age (\%) } & \multicolumn{2}{|l|}{ Sex (\%) } & \multicolumn{2}{|c|}{ Working in (\%) } \\
\hline & $\leq 49$ years & $\geq 50$ years & Female & Male & $\begin{array}{l}\text { Public } \\
\text { sector }\end{array}$ & $\begin{array}{l}\text { Private/public } \\
\text { sector }\end{array}$ \\
\hline \multicolumn{7}{|c|}{ According to the OBGYNs, women are aware of non-contraceptive benefits of COC $(n=187)$ : } \\
\hline Less than $20 \%$ & 61.1 & 72.2 & 62.2 & 71.4 & 79.3 & 58.1 \\
\hline Between $40 \%-50 \%$ & 22.2 & 16.7 & 24.3 & 14.3 & 10.3 & 25.6 \\
\hline Almost $75 \%$ & 13.9 & 8.3 & 8.1 & 14.3 & 6.9 & 14.0 \\
\hline All women & 2.8 & 2.8 & 5.4 & 0.0 & 3.4 & 2.3 \\
\hline \multicolumn{7}{|c|}{ When OBGYNs prescribe a COC, which non-contraceptive benefits influenced the decision? $(n=187)$ : } \\
\hline Improve dysmenorrhea and PMS & 53.0 & 77.2 & 64.7 & 66.6 & 64.3 & 66.7 \\
\hline Reduce acne and hirsutism & 46.9 & 22.9 & 35.3 & 33.3 & 35.7 & 33.0 \\
\hline Reduce ovarian/endometrial cancer risk & 0.0 & 0.0 & 0.0 & 0.0 & 0.0 & 0.0 \\
\hline \multicolumn{7}{|c|}{ Which non-contraceptive benefits are your patients looking for when they procure a COC? $(n=190)$ : } \\
\hline Improve dysmenorrhea and PMS & 27.8 & 21.6 & 28.2 & 20.6 & 30.0 & 20.9 \\
\hline Reduce acne and hirsutism & 25.0 & 21.6 & 20.5 & 26.5 & 26.7 & 20.9 \\
\hline Prevent weight increase & 22.2 & 37.8 & 30.8 & 29.4 & 30.0 & 30.2 \\
\hline Reduce bleeding flow and number of cycles & 25.0 & 18.9 & 20.5 & 23.5 & 13.3 & 27.9 \\
\hline
\end{tabular}

Abbreviations: COC, combined oral contraceptive; OBGYN, obstetrician and gynecologist; PMS, premenstrual syndrome.

contraceptive is highly effective given perfect use (consistent and correct), its effectiveness is lower given typical use, mainly due to the fact that its efficacy is dependent on daily attention and that women frequently forget one or more pills during the cycle intake. ${ }^{16-19}$
Our survey showed that almost $50 \%$ of the participating OBGYNs did not know the failure rate for COCs given typical use, although almost $90 \%$ of the OBGYNs responded that between $30 \%$ and $70 \%$ of their patients forget to take at least one pill per cycle, and almost $50 \%$ reported that $\mathrm{COC}$

Table 4 Questions and answers about risks associated with COC use

\begin{tabular}{|c|c|c|c|c|c|c|}
\hline & \multicolumn{2}{|l|}{ Age (\%) } & \multicolumn{2}{|l|}{ Sex (\%) } & \multicolumn{2}{|c|}{ Working in (\%) } \\
\hline & $\leq 49$ years & $\geq 50$ years & Female & Male & $\begin{array}{l}\text { Public } \\
\text { sector }\end{array}$ & $\begin{array}{l}\text { Private/public } \\
\text { sector }\end{array}$ \\
\hline \multicolumn{7}{|l|}{ Main risk for VTE and COC use $(n=184)$ : } \\
\hline Familiar history of VTE & 0.0 & 3.1 & 0.0 & 1.9 & 0.0 & 1.6 \\
\hline$>35$ years old & 0.0 & 1.6 & 0.0 & 1.9 & 0.0 & 1.6 \\
\hline Personal history of VTE & 0.0 & 0.0 & 25.0 & 17.0 & 26.5 & 17.5 \\
\hline Smoking & 0.0 & 0.0 & 0.0 & 3.8 & 0.0 & 3.2 \\
\hline Obesity & 2.6 & 7.8 & 4.5 & 1.9 & 0.0 & 4.8 \\
\hline All & 97.4 & 87.5 & 70.5 & 73.6 & 73.5 & 71.4 \\
\hline \multicolumn{7}{|c|}{ Which statement about COC use and VTE is incorrect? $(n=184)$ : } \\
\hline The risk is high within the first months of use & 2.3 & 0.0 & 0.0 & 1.9 & 2.9 & 0.0 \\
\hline The risk increases after a pause of 4 weeks in use & 18.2 & 14.6 & 23.1 & 11.3 & 20.6 & 13.8 \\
\hline The risk is independent of the length of use & 63.6 & 64.2 & 66.7 & 52.8 & 47.1 & 66.5 \\
\hline The risk is high with high estrogen levels & 9.1 & 12.5 & 5.1 & 15.1 & 14.7 & 8.6 \\
\hline The role of progestin is still controversial & 6.8 & 18.8 & 5.1 & 18.9 & 14.7 & 12.1 \\
\hline \multicolumn{7}{|l|}{ The incidence of VTE among COC users is $(n=173)$ : } \\
\hline $4 / 10,000$ women/year & 1.8 & 16.7 & 6.1 & 11.5 & 9.3 & 9.0 \\
\hline $9-11 / 10,000$ women/year & 90.9 & 83.3 & 89.8 & 85.2 & 81.4 & 91.0 \\
\hline 15-20/10,000 women/year & 5.5 & 0.0 & 2.0 & 3.3 & 7.0 & 0.0 \\
\hline $21-29 / 10,000$ women/year & 1.8 & 0.0 & 2.0 & 0.0 & 2.3 & 0.0 \\
\hline \multicolumn{7}{|c|}{ According to the OBGYNs, the use of COCs could increase the incidence of cancer of $(n=\mid 84)$ : } \\
\hline Endometrium & 2.8 & 5.9 & 5.3 & 2.9 & 0.0 & 7.3 \\
\hline Cervix & 83.3 & 61.8 & 78.9 & 64.7 & 71.0 & 73.2 \\
\hline Colorectal & 0.0 & 2.9 & 2.6 & 2.9 & 0.0 & 4.9 \\
\hline All of them & 0.0 & 5.9 & 0.0 & 5.9 & 3.2 & 2.4 \\
\hline I have doubts & 13.9 & 23.5 & 13.2 & 23.5 & 25.8 & 12.2 \\
\hline
\end{tabular}

Abbreviations: $\mathrm{COC}$, combined oral contraceptive; OBGYN, obstetrician and gynecologist; VTE, venous thromboembolism. 
users do not know what to do when they forget a pill. Any system that may help women to not forget their pill intake is welcome.

Most of the participants reported that less than $20 \%$ of COC users are aware of the non-contraceptive benefits of the method. Furthermore, the benefits the interviewed OBGYNs were interested in when they prescribed COCs were in general similar to those they reported that women were seeking. The non-contraceptive benefits that the OBGYNs reported are well-known and supported by scientific evidence only for some COC preparations..$^{20-22}$ It is already well-established that not all of the COCs currently on the market improve dysmenorrhea or PMS, and that not all of them reduce acne or hirsutism. ${ }^{20-22}$ Regarding weight gain and hormonal contraceptive use, there is a large body of evidence that weight gain is associated with lifestyle and is not associated with contraceptive intake. ${ }^{23}$

In our survey, none of the OBGYNs reported that they prescribe COCs with the aim of reducing ovarian or endometrial cancer, and almost one-quarter reported doubts about the cancer prevention benefits of COC use. This was more common among older male OBGYNs working in the public sector. The use of COCs has been associated with a protective effect against ovarian and endometrial cancer, and it is estimated that the reduction is $\sim 50 \%$ for 15 years of use. Although the protective effect declines as time passes, a significant effect was observed even a long time after the cessation of use. For endometrial cancer, the relative risk reduction is estimated at $\sim 70 \%$ for 12 years of use, with a decrease upon further use. Even after discontinuing the use of COCs, the risk only begins to rise $>20$ years after last use. ${ }^{24}$

A recent US-based study ${ }^{25}$ conducted with 236 OBGYNs and family practitioners, of whom $93.6 \%$ prescribed hormonal contraceptives, assessed knowledge about hormonal contraceptives and cancer prevention. This study showed that $73.6 \%$ of the respondents were aware of the decreased risk of endometrial cancer with COC use and the increased risk among obese patients (95.5\%). However, only 36.8\% consistently counseled their patients regarding obesity-associated cancer risk. Furthermore, $51.5 \%$ of the OBGYNs reported ovarian or endometrial cancer prevention as a benefit of COCs use and were likely to identify risk factors associated with endometrial cancer. In that study, OBGYNs did not commonly prescribe COCs for ovarian and endometrial cancer prevention.

The OBGYNs that participated in the present survey were aware of the incidence and risk factors associated with COC use, including VTE; nevertheless, most of them were not aware of the fact that the risk is higher during the first months of use and declines significantly with continuous use. ${ }^{26-27}$ VTE is one of the main risks associated with COC use; however, its incidence during COC use is lower than during pregnancy and puerperium.

It is imperative that OBGYNs understand the benefits and risks of hormonal and non-hormonal contraceptive use because well-informed HCPs are able to translate this scientific knowledge for their patients and increase the acceptability, continuation, and effective use of contraceptives that require daily or periodical attention, such as COCs; furthermore, HCPs can help patients to overcome common myths and misconceptions. ${ }^{8-10}$

The role of OBGYNs in COC use is very important because counseling is crucial for adherence and correct use. Counseling must be a constant activity, one that is not only performed during the initial period of contraceptive use, in order to inform women about potential and expected side effects and non-contraceptive benefits. It is also crucial to adopt a new contraceptive method with at least the same contraceptive efficacy immediately after the discontinuation of an old one. It is important that HCPs, mainly OBGYNs and family practitioners, are aware of the low risk and high benefits of the use of many contraceptive methods. COCs are not the exception in this regard.

\section{Conclusion}

Our survey showed that the interviewed LA OBGYNs correctly identified unintended pregnancy as an important health issue. Regarding COCs, they reported that a percentage of their patients frequently forget to take a pill and that women habitually do not know what to do in the case of missed pills. They were not prone to prescribe COCs to reduce the risk of ovarian and endometrial cancer, and almost one-quarter had doubts about the association between pill intake and the risk of cancer development. OBGYNs should counsel their patients regarding the various aspects of COC intake, such as what to do in case of missed pills, risks, and noncontraceptive benefits. In order to provide adequate counseling, it is necessary that OBGYNs be updated regarding all aspects of COC use. Despite the small sample size for a big region like LA, there are some concerns about the knowledge regarding COCs of this sample of OBGYNs. Our results could be useful to medical schools, scientific societies, and national and regional policy makers to increase a continued medical education in this matter, as well as to improve the use of existing national family planning guidelines and the World Health Organization guidelines about contraceptive methods. ${ }^{28,29}$ 


\section{Author contributions}

All authors were involved in the design and development of the study and took part in either drafting the article or revising it critically for important intellectual content. All authors gave final approval of the version to be published.

\section{Disclosure}

The authors report no conflicts of interest in this work.

\section{References}

1. Gipson JD, Koenig MA, Hindin MJ. The effects of unintended pregnancy on infant, child, and parental health: a review of the literature. Stud Fam Plann. 2008;39(1):18-38.

2. Sedgh G, Singh $S$, Hussain R. Intended and unintended pregnancies worldwide in 2012 and recent trends. Stud Fam Plann. 2014;45(3):301-314.

3. Finer LB, Zolna MR. Shifts in intended and unintended pregnancies in the United States, 2001-2008. Am J Public Health. 2014;104 Suppl 1: S43-S48.

4. Amaral G, Foster DG, Biggs MA, Jasik CB, Judd S, Brindis CD. Public savings from the prevention of unintended pregnancy: a cost analysis of family planning services in California. Health Serv Res. 2007; 42(5):1960-1980.

5. Winner B, Peipert JF, Zhao Q, et al. Effectiveness of long-acting reversible contraception. N Engl J Med. 2012;366(21):1998-2007.

6. Bahamondes L, Bottura BF, Bahamondes MV, et al. Estimated disability-adjusted life years averted by long-term provision of long acting contraceptive methods in a Brazilian clinic. Hum Reprod. 2014;29(10): 2163-2170.

7. Reading BF. Growth in World Contraceptive Use Stalling; 215 Million Women's Needs Still Unmet [webpage on the Internet]. Washington (DC): Earth Policy Institute; 2012. Available from: http://www.earthpolicy.org/data_highlights/2012/highlights26. Accessed October 1, 2014.

8. Shulman LP. The state of hormonal contraception today: benefits and risks of hormonal contraceptives: combined estrogen and progestin contraceptives. Am J Obstet Gynecol. 2011;205(4 Suppl):S9-S13.

9. Makuch MY, D Osis MJ, de Pádua KS, Bahamondes L. Use of hormonal contraceptives to control menstrual bleeding: attitudes and practice of Brazilian gynecologists. Int J Womens Health. 2013;5:795-801.

10. Gaudet LM, Kives S, Hahn PM, Reid RL. What women believe about oral contraceptives and the effect of counseling. Contraception. 2004; 69(1):31-36.

11. No authors listed. The TCu 380A IUD and the frameless IUD 'the FlexiGard': interim three-year data from an international multicenter trial. UNDP, UNFPA, and WHO Special Programme of Research, Development, and Research Training in Human Reproduction, World Bank: IUD Research Group. Contraception. 1995;52(2):77-83.

12. Finer LB, Henshaw SK. Disparities in rates of unintended pregnancy in the United States, 1994 and 2001. Perspect Sex Reprod Health. 2006; 38(2):90-96.
13. World Health Organization Guttmacher Institute. Facts on Induced Abortion Worldwide. Geneva: World Health Organization Guttmacher Institute; 2007. Available from: http://www.guttmacher.org/pubs/ fb_IAW.html. Accessed October 25, 2014.

14. Peipert JF, Madden T, Allsworth JE, Secura GM. Preventing unintended pregnancies by providing no-cost contraception. Obstet Gynecol. 2012;120(6):1291-1297.

15. Blumenthal PD, Voedisch A, Gemzell-Danielsson K. Strategies to prevent unintended pregnancy: increasing use of long-acting reversible contraception. Hum Reprod Update. 2011;17(1):121-137.

16. Jones EF, Forrest JD. Contraceptive failure rates based on the 1988 NSFG. Fam Plann Perspect. 1992;24(1):12-19.

17. Henshaw SK. Unintended pregnancy in the United States. Fam Plann Perspect. 1998;30(1):24-29.

18. Fu H, Darroch JE, Haas T, Ranjit N. Contraceptive failure rates: new estimates from the 1995 National Survey of Family Growth. Fam Plann Perspect. 1999;31(2):56-63.

19. Trussell J, Wynn LL. Reducing unintended pregnancy in the United States. Contraception. 2008;77(1):1-5.

20. Blumenthal PD, Edelman A. Hormonal contraception. Obstet Gynecol. 2008;112(3):670-684.

21. Rapkin AJ. YAZ in the treatment of premenstrual dysphoric disorder. J Reprod Med. 2008;53(9 Suppl):729-741.

22. Jensen JT. Evaluation of a new estradiol oral contraceptive: estradiol valerate and dienogest. Expert Opin Pharmacother. 2010;11(7):1147-1157.

23. Gallo MF, Lopez LM, Grimes DA, Carayon F, Schulz KF, Helmerhorst FM. Combination contraceptives: effects on weight. Cochrane Database Syst Rev. 2014;1:CD003987.

24. Grimbizis GF, Tarlatzis BC. The use of hormonal contraception and its protective role against endometrial and ovarian cancer. Best Pract Res Clin Obstet Gynaecol. 2010;24(1):29-38.

25. Horst KE, Modesitt SC. Hormonal contraceptive use for endometrial cancer prevention: physician attitudes and practices. Obstet Gynecol. 2014;123 Suppl 1:183S

26. Peragallo Urrutia R, Coeytaux RR, McBroom AJ, et al. Risk of acute thromboembolic events with oral contraceptive use: a systematic review and meta-analysis. Obstet Gynecol. 2013;122(2 Pt 1):380-389.

27. Emmerich J, Thomassin C, Zureik M. Contraceptive pills and thrombosis: effects of the French crisis on prescriptions and consequences for medicine agencies. J Thromb Haemost. 2014;12(9):1388-1390.

28. World Health Organisation, Department of Reproductive Health Medical eligibility criteria for contraceptive use. Geneva: World Health Organization; 2010. Available from: http://www.who.int/ reproductivehealth/publications/family_planning/9789241563888/en/. Accessed September 2014.

29. World Health Organisation, Department of Reproductive Health Selected practice recommendations for contraceptive use. Geneva: World Health Organization; 2004. Available from: http://whqlibdoc. who.int/publications/2004/9241562846.pdf?ua=1. Accessed September 2014.
International Journal of Women's Health

\section{Publish your work in this journal}

The International Journal of Women's Health is an international, peerreviewed open-access journal publishing original research, reports, editorials, reviews and commentaries on all aspects of women's healthcare including gynecology, obstetrics, and breast cancer. The manuscript management system is completely online and includes

\section{Dovepress}

a very quick and fair peer-review system, which is all easy to use. Visit http://www.dovepress.com/testimonials.php to read real quotes from published authors. 